\title{
Investigation of foreign exchange rate risks of Borsa Istanbul airline passenger transpor- tation companies
}

\author{
Mehmet Beyazgül ${ }^{1}$, Erdinç Karadeniz ${ }^{2}$
}

\begin{abstract}
Recently, the high volatility in the exchange rates in Turkey have brought the importance of taking measures to exchange rate risk for the companies in real sector. The effect of exchange rate changes can be higher in sectors that income or expenses are in foreign currencies or that use foreign currency in their activities. In the tourism sector, the fact that the airline passenger transportation companies are operated in international activities due to their income and expenditure based on currency is an important factor that could exposed to exchange rate risk. The purpose of this study is to evaluate the exchange rate risks by examining the financial reports that published by the airline passenger transportation companies whose shares are traded in the Borsa Istanbul. In accordance with this purpose the financial reports of two airline passenger transportation companies whose shares are traded in the Borsa Istanbul were examined for 2017. As a result of the study, it was determined that the publicly traded airline passenger transportation companies in Borsa Istanbul had currencies that US Dollar, Euro, Turkish Lira, British Pound and Japanese Yen and both companies have been exposed to exchange rate risk. In the study, it has determined that according to the 8-month average of the year 2018, assets of company A has lost value and assets of company $B$ has gained value, affected by the change in foreign exchange rates. In addition, in the study it has been determined that a company has a small amount of derivative products based on currency and the other does not have any derivative products based on currency.
\end{abstract}

Keywords: Exchange Rates, Exchange Rate Risk, Airline Companies, Borsa Istanbul.

\section{Borsa İstanbul havayolu yolcu taşımacılığı şirketlerinin döviz kuru risklerinin incelen- mesi}

$\ddot{\partial} z$

Son dönemde Türkiye'deki döviz kurlarında yaşanan yüksek oynaklık, reel sektördeki işletmelerde döviz kuru riskine yönelik önlem alınmasının önemini gündeme getirmiştir. Faaliyetlerinde yabancı para kullanan, gelir veya giderleri yabancı para cinsinden olan sektörlerde döviz kurundaki değişimlerin etkisi daha büyük olabilmektedir. Bu sektörlerden biri olan turizm sektöründe özellikle havayolu yolcu taşımacıllğ $\mathrm{l}$ şirketlerinin uluslararası faaliyetlerde bulunması nedeniyle gelir-giderlerinin dövize dayalı olması, bu şirketlerin kur riskine maruz kalmasına yol açabilecek önemli bir etmendir. Bu çalışmanın amacı, payları Borsa İstanbul'da işlem gören havayolu yolcu taşımacılığl şirketlerinin yayınladıkları finansal raporlar ve kur riski yönetimiyle ilgili beyanları üzerinden inceleyerek döviz kuru risklerini ve buna yönelik hangi önlemlerin alındı̆̆ını değerlendirmektir. Bu amaç doğrultusunda payları Borsa İstanbul'da işlem gören ve havayolu yolcu taşımacıllğ faaliyetinde bulunan iki şirketin 2017 yllına ait finansal raporları incelenmiştir. Çalışma neticesinde Borsa İstanbul havayolu yolcu taşımacılı̆̆ı şirketlerinin ABD Dolarl, Avro, Türk Lirası, Ingiliz Sterlini ve Japon Yeni para birimlerinden dövize sahip olduğu ve her iki şirketin de kur riskine maruz kaldığı tespit edilmiştir. Çalışmada, 2018 yılı 8 aylı ortalama verilere göre, A şirketinin varlıklarının döviz kurlarındaki değişimden etkilenerek dĕger kaybettiği, B şirketinin ise varlıklarının değer kazandığ ortaya çıkmıştır. Ayrıca çalışmada A şirketinin az miktarda dövize dayalı türev ürüne sahip olduğu, B şirketinin ise dövize dayalı herhangi bir türev ürüne sahip olmadığı belirlenmiştir.

Anahtar sözcükler: Döviz Kurları, Döviz Kuru Riski, Havayolu Şirketleri, Borsa İstanbul.

$\begin{array}{ll}\text { Geliş Tarihi } & : 27.09 .2018 \\ \text { Kabul Tarihi } & : 01.03 .2019\end{array}$

Alıntı için: Beyazgül, M., Karadeniz, E. (2019). Investigation of foreign exchange rate risks of Borsa Istanbul airline passenger transportation companies. Journal of Tourism Theory and Research, 5(2), 191-202.

\footnotetext{
${ }^{1}$ Sorumlu Yazar, Arş. Gör., Mersin Üniversitesi, Turizm Fakültesi, Turizm İşletmeciliği Bölümü, Mersin / Türkiye, e-mail: $\underline{\text { mehmet- }}$ beyazgul@mersin.edu.tr

${ }^{2}$ Doç. Dr., Mersin Üniversitesi, Turizm Fakültesi, Turizm İşletmeciliği Bölümü, Mersin / Türkiye, e-mail: ekaradeniz@mersin.edu.tr 


\section{Giriş}

Bretton Woods sabit kur sisteminin 1973'de çökmesinin ardından, gelişmiş ülke ekonomilerinin çoğu dalgalı kur sistemine geçmiştir (Helleiner, 1996:103). 1980'lerden itibaren gelişmekte olan ülkelerin de dalgalı kur rejimine geçmesi, ekonomi politikalarının liberalleşmesi, dıș borçların artması ve ihracata dayalı kalkınma programlarının izlenmesi ile birlikte küresel ölçekte finansal işlemlerin hacmi olağanüstü boyuta ulaşmıştır (Altay, 2014:312). Ülkelerin döviz kurlarının serbest piyasalarda arz ve talebe göre belirlendiği dalgalı kur sistemi ile birlikte döviz kurlarındaki beklenmeyen fiyat hareketleri, ülke ekonomileri, şirketler ve finansal kurumlar için kur riskini meydana getirmektedir.

Kur riski genel olarak beklenmedik döviz kuru değişimlerinin firma değeri üzerindeki etkisi olarak tanımlanmaktadır. Daha açık bir ifade ile kur riski, beklenmedik kur hareketleri sonucunda şirketlerin nakit akışlarında, varlık ve yükümlülüklerinde, net kar marjında ve bu doğrultuda şirketin hisse senetlerinin piyasa fiyatında doğrudan veya dolaylı olarak meydana gelen beklenmeyen değişimler olarak tanımlanmaktadır (Büberkökü, 2014:1). Genel olarak döviz kuru riski üç farklı şekilde ortaya çıkabilir. Bunlar işlem riski, çevirme riski ve ekonomik risk olarak adlandırılmaktadır. İşlem riski, kurlardaki değişimin borç ve alacakların yerel para birimi değeri üzerindeki etkilerinden kaynaklanmaktadır (Altay, 2014:313). İşlem riski, daha çok kısa süreli olarak gerçekleştiğinden, türev piyasalardaki korunma yöntemlerinin kullanılması bu riski ortadan kaldırabilir (Mutluay ve Turaboğlu, 2013: 60). Çevirme riski, yabancı bir iştirakin ana şirketin bilançosuna konsolide edilmesinde kurlardaki değişimin etkisinden kaynaklanmaktadır (Altay, 2014:313). Çevirme riskinden korunmak için zayıf para biriminden varlıkların azaltılıp, yükümlülüklerin arttırılması ve güçlü para biriminden varlıkların tutulup, yükümlülüklerin azaltılmas1 önerilmektedir (Shapiro, 2013:115; Mutluay ve Turaboğlu, 2013:60). Ekonomik risk ise şirketlerin gelirlerinin ve giderlerinin döviz kuru değişimlerinden etkilenmesi nedeniyle ortaya çıkmaktadır (Altay, 2014:313). Döviz kurundaki değişimlerin şirketleri ekonomik yönden etkilemesi uzun vadede gerçekleștiğinden, türev piyasalardaki korunma yöntemlerinin ekonomik riskin azaltılmasında zayıf kaldığı belirtilmektedir (Mutluay ve Turaboğlu, 2013:60).
Küresel olarak döviz piyasalarına bakıldığında bu piyasalarda ülkelerin hazinelerinin, merkez bankalarının, bankaların, diğer finans sektörü aktörlerinin yanında reel sektörde faaliyet gösteren işletmelerin ve hatta bireysel yatırımcılar gibi çok farklı özelliklere sahip birimlerin işlem yaptığı görülmektedir (Altay, 2014:313). Döviz piyasaları, spot işlemlerin yapıldığı spot döviz piyasaları ve vadeli işlemlerin yapıldığı döviz türev piyasaları olarak ikiye ayrılmaktadır. Spot döviz piyasalarında döviz alım ve satım işlemlerinde teslimat, işlem tarihinden itibaren iki işgünü içerisinde gerçekleşmektedir. Türev döviz piyasalarında ise döviz alım ve satım işlemlerinde teslimat vade tarihinde gerçekleşmektedir. Türev döviz piyasalarında yapılan işlemler; Döviz Forward Sözleşmesi, Döviz Swap Sözleşmesi, Döviz Futures Sözleşmesi ve Döviz Opsiyon Sözleşmesi olarak dört farklı şekilde gerçekleştirilir (Akkaş, 2015: 6). Döviz kuru riskinin sağlıklı bir şekilde yönetilebilmesi için öncelikle kurları etkileyen faktörlerin bilinmesi, riskin ölçülerek etkilerinin öngörülmesi buna göre riskten kaçınma, riski kabul etme, riski azaltma veya riskten korunma politikalarından birine karar verilmesi ve buna uygun risk yönetimi araçlarının kullanılması gerekmektedir (Altay, 2014:313).

Özellikle 2018 y1lında gelişmekte olan ülkelerde para birimlerindeki değer kayıpları, yükselen petrol fiyatları ve diş ticarette küresel ölçekte artan korumac1lık söylemleri nedeniyle büyüme görünümü ülkeler arasında farklılaşma gösterebilmektedir. Amerikan Merkez Bankasının (Fed) para politikasındaki normalleşme sürecini hızlandırma ihtimalinin belirginleşmesi, ABD tahvil getirilerini arttırmakta ve ABD dolarındaki yükselişi hızlandırarak küresel finansal piyasalarda dalgalanmalara yol açabilmektedir. 2018 yılının ikinci çeyreğinde küresel finansal piyasalarda artan oynaklıklar ve Türkiye'nin risk primlerindeki yükselişler, yurt içi belirsizlikler ve cari açık ile enflasyonda görülen yükseliş Türkiye'nin ülke risk primi ile döviz kurlarına dair göstergelerin olumsuz gelişmesine neden olmaktadır. Son dönemde Türkiye'deki döviz kurlarında yaşanan yüksek oynaklığın döviz açığı bulunan şirketlerde zarara yol açtığı görülmektedir. Özellikle dolarda günlük $\% 2-\% 5$ arasında meydana gelen fiyat değişimleri hammaddeyi dolar ile alıp iç piyasaya TL cinsinden satan reel sektördeki işletmeleri zarara uğratabilmektedir. Bununla beraber döviz kurlarındaki artış, sabit maliyetlerin de yükselmesine neden olmakta 
ve özellikle KOBİ statüsündeki işletmelerin maliyet hesaplamas1 yapmasını zorlaştırabilmektedir. 2018 Mayıs itibariyle Türkiye'nin toplam kısa vadeli dış borç stoku 123,3 milyar dolar olarak gerçekleşmiştir. TCMB verilerine göre, bu dönemde bankalar kaynaklı kısa vadeli dış borç stoku \%2 artarak 68,1 milyar dolar olurken, diğer sektörlerin kısa vadeli dış borç stoku \% 8,5 artarak 55.1 milyar dolar düzeyinde gerçekleşerek tarihi bir değer almıştır. Bu veriler Türkiye'deki reel sektörün döviz kuru riskinin ne kadar yüksek olduğunu göstermektedir (Businessht, 2018). Türkiye'de döviz kurlarından en fazla etkilenen sektörlerden birisi de turizm sektörüdür. İşletme gelirlerinin tamamına yakının yabanc1 paralarla yapılması nedeniyle, döviz kurlarındaki değişimler aynı șekilde turizm ișletmelerine yansımaktadır (Kutukız, 2005: 199). Özellikle havayolu yolcu taşımacılığı şirketlerinin yakıt maliyetlerinin dövize dayalı olması, bu şirketlerin döviz kurlarındaki oynaklık nedeniyle zarara uğramalarına neden olabilmektedir. Bu bağlamda çalışmanın amacı, payları Borsa İstanbul'da işlem gören havayolu yolcu taşımacılığı şirketlerinin faaliyet raporlarını inceleyerek döviz kuru risklerini ve buna yönelik hangi önlemlerin alındığını değerlendirmektir. Buna göre çalışma üç bölümden oluşmaktadır. Birinci bölümde konuyla ilgili literatür taraması yer almaktadır. Çalışmanın ikinci bölümünde yöntem ve bulgular yer almakta, üçüncü bölümde ise genel bir değerlendirme yapılarak öneriler sunulmaya çalışılmıştır.

\section{Literatür}

Konuyla ilgili yapılan literatür incelemesi sonucunda kur riski ile ilgili bankacılık, imalat sektörünün çeşitli alt sektörleri ve turizm sektöründe, bunun yanında kur riskinin ülkelerin dış ticaretleri üzerindeki etkisini inceleyen çalışmaların olduğu görülmektedir. Ancak spesifik olarak Türkiye'deki havayolu yolcu taşımacılığı şirketlerinin kur riskinin incelendiği bir çalışmaya tarafımızca rastlanmamıştır. Literatür incelemesi sonucunda tarafımızca ulaşılan çalışmalar aşağıda sunulmuştur.

Doğukanl1, Özmen ve Yücel (2010), İMKB'deki sektörlerin döviz kuru duyarlılıklarının belirlenmesi amacıyla bir çalışma gerçekleştirmişlerdir. Çalışmada IMKB'deki 3 ana ve 15 alt sektörün hisse senedi endeksleri, Avro para biriminin kullanılmaya başlandığı tarih dikkate alınarak Ocak 1999-Haziran 2009 döne- mine ait günlük döviz kurlarına karşı duyarlılıkları Johansen eşbütünleşme testi ile analiz edilmiştir. Çalışma neticesinde analize dâhil edilen sektörler ile döviz kurlarının uzun dönemde birlikte hareket ettikleri ifade edilmiştir. Ayrıca, döviz kuru duyarlılıklarının sektörler arasında farklılık gösterdiği de ayrıca belirtilmiştir.

Ünal ve Altın (2010), şirketlerin piyasa değeri ile net döviz pozisyonları arasındaki ilişkinin ortaya konulması amacıyla gerçekleştirdikleri çalışmada Türk Otomotiv Sanayi şirketlerinin 2004-2008 yıllarına ait üçer aylık verilerini panel veri analizi ile incelemişlerdir. Çalışma neticesinde Türk Otomotiv Sanayi içerisinde yer alan şirketlerin piyasa değerleriyle net döviz pozisyonları arasında anlamlı bir ilişki bulunamadığı ve bu sonucun önceki birçok çalışma ile uyumlu olduğu belirtilmiştir.

Mutluay ve Turaboğlu (2013), döviz kurlarındaki değişimin şirketler üzerindeki etkisini ölçmeyi amaçladıkları çalışmalarında İMKB'deki 55 şirketin 19972007 dönemine ait verilerini regresyon modeli ile incelemişlerdir. Çalışma sonucunda şirketlerin performansının döviz kurlarındaki değişimden gecikmeli olarak etkilendiği ve etkilenme düzeyinin, yurt dışına yapılan satışlar ile ters yönlü ilişkili olduğu belirtilmiştir.

Doğanay (2016), sektörel düzeyde tütüncülük endüstrisinin döviz kurlarındaki değişiminden etkilenmesi, döviz kuru bazında para pozisyon yapısının belirlenmesi ve kur riski yönetimine yönelik yaklaşımının belirlenmesi amacıyla tütüncülük endüstrisinde yer alan 20 ayrı şirkete anket uygulamıştır. Çalışma neticesinde sistematik şekilde kur riskinden korunmaya yönelik uygulaması olan şirketlerin sınırlı kaldığı, şirketlerin genellikle işletme içi çözümler üretme yolunu seçtikleri belirtilmiştir.

Gökçe ve Sarıtaş (2017), döviz kurunda yaşanan değişimin, özel sermayeli bankaların bilançosundaki kalemlerdeki etkisini araştırmışlardır. Çalışmada özel sermayeli bankalar grubunun banka bilançolarında yer alan kalemlerden net kar-zarar, Türk Lirası cinsinden nakit değerler ve Merkez Bankası kalemi, Türk Lirası cinsinden mevduat, takipteki krediler, karşılıklar, özkaynaklar, genel aktif toplamı ve krediler ve alacaklar kalemleri ana değişkenler olarak belirlenmiştir. Çalışma 2002 yılının Aralık ayı ile 2012 yılı Temmuz ayı dönemini kapsamaktadır. Çalışmada döviz kurundaki değişim hesaplanırken Amerikan Doları (USD) baz 
alınmıştır. Regresyon yöntemlerinden kantil regresyon yönteminin kullanıldığı çalışmada döviz kurunda yaşanan artışın; bankaların takipteki kredi miktarını, net kar/ zarar kalemini, özkaynak miktarını, Türk Lirası mevduatını ve aktif büyüklüğü arttırdığı sonucu ortaya çıkmıştır.

Kutukız (2005), döviz kurundaki değişimlerin doğurduğu risklere karşı turizm sektöründe birinci derecede önemli görülen riskleri ortaya koymak amaciyla bir çalışma yapmıştır. Çalışmada Muğla Bölgesi'nde çoğunluğunun KOBİ olduğu 120 şirkete anket uygulaması yapılmıştır. Çalışma sonucunda ankete katılan şirketlerin 2001 yılı ve öncesi dönemde en önemli risk olarak faiz riskini gördükleri, 2001 yılından sonra ise en önemli risk olarak kur riskini gördükleri belirtilmiştir. Çalışmada ayrıca şirketlerin risklere karşı korunma ve diğer amaçlarla vadeli işlem yapmadıkları, türev ürünler konusunda gerekli bilgiye sahip olmadıkları ortaya konulmuştur.

Kılıç ve Bayar (2014), döviz kurundaki değişimin Türkiye'deki turizm gelirleri ve harcamalarına etkisini araştırdıkları çalışmada, 1994 yılı Ocak ayı ile 2013 yılı Ağustos ayı arasındaki dönemdeki döviz kurundaki ve turizm gelir ve harcamalarındaki oynaklığı incelemişlerdir. Johansen eșbütünleşme testinin kullanıldığ çalışmada döviz kurundaki değişimler ile turizm gelir ve harcamalarının uzun dönemli eşbütünleşik olduğu sonucuna varılmıştır.

\section{Yöntem}

Çalışmada ikincil veriler kullanılarak oransal analizler gerçekleştirilmiştir. Finansal tablolarda yer alan iki kalem arasındaki ilişkinin matematiksel olarak ifadesine oran veya rasyo denilmektedir (Ceylan ve Korkmaz 2008).

\subsection{Araştırmanın amacı}

Çalışmanın amacı, payları Borsa İstanbul'da işlem gören havayolu yolcu taşımacılığı şirketlerinin faaliyet raporlarını inceleyerek döviz kuru risklerini değerlendirmektir.

\section{2. Örneklem ve veri toplama}

Çalışmanın amacı doğrultusunda payları Borsa İstanbul (BIST)'da işlem gören havayolu yolcu taşımac1lığı şirketlerinin 2017 dönemine ait finansal tabloları incelenmiştir. Türkiye'de faaliyet gösteren halka açık havayolu yolcu taşımacılı̆̆ muyu Aydınlatma Platformu (2018), Şirketlerin kendi web sitelerinde yayımladıkları faaliyet raporları ve Thomson \& Reuters EIKON veri tabanından erişilmiştir. Thomson \& Reuters EIKON veri tabanı aboneliği Mersin Üniversitesi Bilimsel Araştırma Projeleri Fonu tarafından desteklenerek sağlanmıştır. (Proje Numaralar1: 2017-2-TP3-2655, 2017-2-TP3-2656 ve 2017-2TP3-2657).

Türkiye'de faaliyet gösteren 2 halka açı havayolu yolcu taşımacılığı şirketi bulunmaktadır. Söz konusu şirketler Türk Hava Yolları A.O. ve Pegasus Hava Taşımacılı̆̆ 1 A.Ş. 'dir. Çalışmada şirketlerin bulguları yorumlanırken herhangi bir spekülasyona yol açmamak adına şirketler “A, B” olarak kodlanmıştır.

Bu çalışma Mersin Üniversitesi Bilimsel Araştırma Projeleri Fonu tarafindan desteklenmiştir. (Proje Numaralar1: 2017-2-TP3-2655, 2017-2-TP3-2656 ve 2017-2-TP3-2657).

\section{Bulgular}

Çalışmanın amacı doğrultusunda öncelikle Türkiye'deki halka açık havayolu yolcu taşımacılığı şirketlerinin 2017 y1lına ait finansal durum tablolarındaki nakit ve nakit benzeri varlıklarının döviz dağılımı değerlendirilmiştir. Daha sonra bu şirketlerin varlık ve yükümlülüklerinin yabancı para dağılımları incelenmiş ve bu şirketlerin döviz kuru riskleri yorumlanmaya çalişılmıştır.

Çalışmaya dâhil edilen halka açık havayolu taşımac1lı̆̆1 şirketlerinin döviz dağılımları incelenmeden önce bu şirketlerin kullandığ fonksiyonel para birimleri incelenmiştir. Analize dâhil edilen şirketlerin 2017 yılı finansal raporlarına bakıldığında A şirketinin ana operasyonu olan tarifeli uçuş gelirlerinin önemli bir kısmının Avrupa uçuşlarından oluşması ve şirket finansal borçlarında Avro'nun önemli ağırlığı olması nedeniyle fonksiyonel para birimin Avro olarak belirlendiği görülmüştür. B şirketinin 2017 yılı finansal raporunda ise şirketin faaliyetleri üzerinde ABD Doları'nın etkisinin önemli olduğu ve şirketle alakalı durumların altında yatan ekonomik özü yansıtan para biriminin ABD Doları olduğu belirtilmiştir. Buna göre çalışmanın bulguları yorumlanırken A şirketinde Avro dışındaki para birimleri yabancı para olarak dikkate alınırken B şirketinde ABD Doları dışındaki para birimleri 
yabancı para olarak dikkate alınacaktır. Ancak Türkiye'de finansal tablolar Türk Ticaret Kanunu (TTK)'nun 70. maddesi uyarınca Türk Lirası cinsinden sunulduğundan bu çalışmada da tablolar Türk Lirası cinsinden sunulacaktır. Çalışmada incelenen şirketlerin nakit ve nakit benzeri varlıklarının dağılımları tablo 1 'de verilmiştir.

Tablo 1. Türkiye'deki halka açık havayolu yolcu taşımacılığı şirketlerinin 2017 yılına ait nakit ve nakit benzeri varlıklarının dağılımları

\begin{tabular}{|l|r|r|r|r|}
\cline { 2 - 5 } Milyon TL & \multicolumn{2}{|c|}{ A } & \multicolumn{2}{|c|}{ B } \\
\cline { 2 - 5 } & \multicolumn{1}{|c|}{ Tutar } & \multicolumn{1}{c|}{ Yüzde } & \multicolumn{1}{c|}{ Tutar } & Yüzde \\
\hline Nakit ve nakit benzerleri & 1.988 & 0,25 & 7.132 & 0,10 \\
\hline -Kasa & 0,734 & 0,00 & 9 & 0,00 \\
\hline -Banka & 1.987 & 1,00 & 7.123 & 1,00 \\
\hline -Vadesiz Mevduatlar & 58 & 0,03 & 453 & 0,06 \\
\hline -Vadeli Mevduatlar & 1.930 & 0,97 & 6.67 & 0,94 \\
\hline Dönen Varlıklar & 3.097 & 0,38 & 13.699 & 0,20 \\
\hline TOPLAM VARLIKLAR & 8.088 & 1,00 & 68.647 & 1,00 \\
\hline
\end{tabular}

Tablo 1 incelendiğinde 2017 yılında A şirketinin toplam varlıklarının \%38'inin dönen varlıklardan oluştuğu ve \%25'inin de nakit ve nakit benzeri varlıklardan oluştuğu görülürken, B şirketinin ise toplam varlıklarının \%20'sinin dönen varlıklardan oluştuğu ve \%10'unun da nakit ve nakit benzeri varlıklardan oluştuğu görülmektedir. Buna göre 2017 y1lında bu şirketlerin özellikle de A şirketinin dönen varlıklarının büyük kısmının nakit ve nakit benzeri varlıklardan oluştuğu söylenebilir. A ve B şirketlerinin nakit ve nakit benzerleri varlıklarının dağılımı incelendiğinde ise bu şirketlerin neredeyse tüm nakit varlıklarını banka hesaplarına bağlı vadeli mevduat hesaplarında tuttukları ortaya çıkmaktadır. Buna göre bu şirketlerin ellerindeki nakit varlıkları bankalardaki çeşitli faiz oranlarından vadeli mevduat hesaplarında değerlendirdikleri söylenebilir. A ve B şirketlerinin vadeli mevduat hesaplarında yer alan nakit varlıklarının para birimine göre dağ 11 เmları tablo 2'de verilmiştir.

Tablo 2. Türkiye'deki halka açık havayolu yolcu taşımacılığı şirketlerinin 2017 yılına ait vadeli mevduat hesaplarının para birimi açısından dağılımları

\begin{tabular}{|l|r|r|r|r|}
\hline \multirow{2}{*}{ Milyon TL } & \multicolumn{2}{|c|}{ A } & \multicolumn{2}{|c|}{ B } \\
\cline { 2 - 5 } & Tutar & Yüzde & Tutar & Yüzde \\
\hline Vadeli Mevduatlar & 1.930 & 1,00 & 6.670 & 1,00 \\
\hline -ABD Doları mevduatlar & 1.687 & 0,87 & 535 & 0,08 \\
\hline -TL mevduatlar & 49 & 0,03 & 153 & 0,02 \\
\hline -Avro mevduatlar & 182 & 0,09 & 5.982 & 0,90 \\
\hline -İngiliz Sterlini mevduatlar & 9 & 0,00 & 0 & 0,00 \\
\hline -İsviçre Frang1 mevduatlar & 2 & 0,00 & 0 & 0,00 \\
\hline
\end{tabular}

Tablo 2 incelendiğinde 2017 y1lında A şirketinin vadeli mevduatlarının \%87'sinin ABD Dolar1, \%9'unun Avro, \%3'ünün Türk Liras1 ve küçük bir kısmının ise İngiliz Sterlini ve İsviçre Frangı cinsinden olduğu görülmektedir. Buna göre 2017 yılında A şirketinin vadeli mevduat hesaplarının çok büyük kısmının şirketin fonksiyonel para birimi olan ABD Doları cinsinden oluştuğu bunun dişında şirketin döviz cinsinden elde tuttuğu vadeli mevduatın büyük bir kısmının Avro'dan oluştuğu ortaya çıkmıştır. B şirketinin 2017 yılına ait vadeli mevduat hesabı incelendiğinde ise şirketin vadeli mevduatlarının \%90'ının Avro, \%8'inin ABD Doları, \%2'sinin Türk Lirası cinsinden olduğu görülmektedir. Buna göre B şirketinin vadeli mevduat hesaplarının çok büyük kısmının şirketin fonksiyonel para birimi olan Avro cinsinden oluştuğu bunun d1şında şirketin döviz cinsinden elde tuttuğu vadeli mevduatın büyük bir kısmının ABD Dolar'ından oluştuğu ortaya çıkmıştır. Yine tablo 2'de her iki şirketin de birbirine yakın oranda Türk Lirası para cinsinden vadeli mevduat hesaplarının olduğu ortaya çıkmaktadır.

Tablo 1 ve 2'de görüldüğü üzere 2017 yılında A ve B şirketlerinin dönen varlıklarının büyük kısmının nakit ve nakit benzeri varlıklardan oluştuğu ve bunun büyük kısmının bu şirketlerin kendi fonksiyonel para birimlerinden oluştuğu görülmektedir. Bununla birlikte A ve B şirketlerinin nakit varlıklarının az miktardaki kısmını oluşturan yabancı para varlıklarının bu şirketlerin günlük faaliyetlerini sürdürmeleri ve yabancı para yükümlülüklerini ödeme gerekçesi ile elde tutulduğu düşünülmektedir. Sonuç olarak A ve B şirketlerinin ellerinde bulundurdukları yabancı para cinsinden varlıkların vadeli mevduat faizi getirisine sahip olduğu ve varlıklar içindeki oranlarının düşük oldukları göz önünde bulundurulduğunda bu şirketlerin nakit ve nakit benzeri varlıklar itibariyle kur riskinin düşük olduğu söylenebilir.

Çalışmanın temel amacı doğrultusunda Türkiye'deki halka açık havayolu yolcu taşımacılığ şirketlerinin 2017 yılına ait döviz kuru risklerinin incelenmesi amaciyla söz konusu şirketlerin finansal raporlarındaki 'Finansal Araçlardan Kaynaklanan Risklerin Niteliği' bölümündeki 'Kur Riski Yönetimi' tablolarından Tablo 3 düzenlenmiştir.

Tablo 3'de A ve B şirketlerinin kur riskine sebebiyet veren yabanc1 para cinsinden parasal ve parasal olmayan varlıklarının ve parasal ve parasal olmayan yükümlülüklerinin 2017 yılı dönem sonu bilanço tarihi 
itibarıyla dağılımları TL'ye çevrilmiş şekilde verilmiştir. Aktif ve pasif kalemler, bilanço tarihi itibarıyla Türkiye Cumhuriyet Merkez Bankası (TCMB) alış kurlarıla çevrilmiştir;

31 Aralik 2017:

- 1 ABD Doları (USD) =3,7719 TL,

- 1 Avro (EUR) = 4,5155 TL,

- 1 İngiliz Sterlini (GBP) = 5,0803 TL

- 1 Japon Yeni $(\mathrm{JPY})=3,3421 \mathrm{TL}$
Tablo 3 incelendiğinde A şirketinin yabancı para cinsinden finansal varlık ve yükümlülüklerinin $\mathrm{ABD}$ Doları, Türk Lirası (TL) ve İngiliz Sterlini para birimlerinden oluştuğu, B şirketinin ise Avro, Türk Lirası (TL) ve Japon Yeni (JPY) para birimlerinden oluştuğu görülmektedir. Tablo 3'de ayrıca A şirketinin ABD Doları ve İngiliz Sterlini döviz cinslerinden türev ürünlerine sahip olduğu görülmektedir. B şirketinin ise herhangi bir döviz cinslerinden türev ürününe sahip olmadığ 1 tespit edilmiştir.

Tablo 3. Türkiye'deki halka açık havayolu yolcu taşımacılığı şirketlerinin 2017 yılına ait yabancı para cinsinden finansal varlık ve yükümlülüklerinin dağılımı

\begin{tabular}{|c|c|c|c|c|c|c|c|c|}
\hline \multirow[t]{2}{*}{ Milyon TL } & \multicolumn{4}{|c|}{$\mathbf{A}$} & \multicolumn{4}{|c|}{ B } \\
\hline & $\begin{array}{l}\text { ABD Do- } \\
\text { lar1 }\end{array}$ & $\mathrm{TL}$ & $\begin{array}{l}\text { İngiliz } \\
\text { Sterlini }\end{array}$ & $\begin{array}{l}\text { TL Top- } \\
\text { lam }\end{array}$ & Avro & $\mathrm{TL}$ & JPY & Toplam \\
\hline Dönen Varlıklar & $2.337,34$ & 134,57 & 15,66 & $2.487,57$ & $7.749,00$ & $1.222,00$ & 50,00 & $9.021,00$ \\
\hline Duran Varlıklar & 261,34 & 0,67 & 0,10 & 262,11 & 353,00 & 14,00 & & 367,00 \\
\hline Toplam Varlıklar & $2.598,68$ & 135,24 & 15,76 & $2.749,68$ & $8.102,00$ & $1.236,00$ & 50,00 & $9.388,00$ \\
\hline Kısa Vadeli Yükümlülükler & 832,15 & 158,01 & 2,14 & 992,31 & $2.872,00$ & $4.658,00$ & 853,00 & $8.383,00$ \\
\hline Uzun Vadeli Yükümlülükler & $1.193,15$ & 0,00 & 0,00 & $1.193,15$ & $13.381,00$ & 515,00 & $7.905,00$ & $21.801,00$ \\
\hline Toplam Yükümlülükler & $2.025,30$ & 158,01 & 2,14 & $2.185,45$ & $16.253,00$ & $5.173,00$ & $8.758,00$ & $30.184,00$ \\
\hline $\begin{array}{l}\text { Net Yabancı Para Varlık/Yükümlü- } \\
\text { lük Pozisyonu }\end{array}$ & 573,38 & $-22,77$ & 13,62 & 564,22 & $-8.151,00$ & $-3.937,00$ & $-8.708,00$ & $-20.796,00$ \\
\hline $\begin{array}{l}\text { Aktif Karakterli Döviz Cinsi Türev } \\
\text { Ürün }\end{array}$ & 61,14 & - & - & 61,14 & - & - & - & - \\
\hline $\begin{array}{l}\text { Pasif Karakterli Döviz Cinsi Türev } \\
\text { Ürün }\end{array}$ & - & - & $-60,96$ & $-60,96$ & - & - & - & - \\
\hline $\begin{array}{l}\text { Döviz Cinsi Türev Araçların Net } \\
\text { Varlık/Yükümlülük Pozisyonu }\end{array}$ & 61,14 & - & $-60,96$ & 0,18 & - & - & - & - \\
\hline
\end{tabular}

Çalışmaya dâhil edilen şirketlerin yabancı para cinsinden finansal varlık ve yükümlülükleri incelendiğinde A şirketinin yaklaşık 2,6 milyar TL değerinde ABD Doları cinsinden finansal varlığının bulunduğu bunun 2,3 milyar TL'sinin dönen varlıklardan oluştuğu görülmektedir. Diğer taraftan A şirketinin yaklaşık 2 milyar TL değerinde ABD Doları cinsinden finansal yükümlülüğ̈üün bulunduğu ve bunun da yaklaşık 1,9 milyar TL'sinin uzun vadeli yükümlülüklerden oluştuğu görülmektedir. Buna göre A şirketinin 2017 yılı dönem sonu itibariyle 573,38 milyon TL değerinde ABD Doları cinsinden net döviz pozisyonu fazlası olduğu ortaya çıkmıştır. Yine A şirketinin 135,24 milyon TL değerinde Türk Lirası cinsinden finansal varlığının bulunduğu bunun 134,57 milyon TL'sinin dönen varlıklardan oluştuğu görülmektedir. Diğer taraftan A şirketinin 158 milyon TL değerinde Türk Lirası cinsinden finansal yükümlülüğünün bulunduğu bunun tamam1- nın kısa vadeli yükümlülüklerden oluştuğu görülmektedir. Buna göre A şirketinin 2017 y1lı dönem sonu itibariyle 22,77 milyon TL değerinde Türk Lirası cinsinden net döviz pozisyonu açığı olduğu ortaya çıkmıştır. A şirketinin İngiliz Sterlini para biriminden varlık ve yükümlülüklerine bakıldığında 15,76 milyon TL değerinde İngiliz Sterlini cinsinden finansal varlığının bulunduğu bunun hemen hemen tamamının dönen varlıklardan oluştuğu görülmektedir. Diğer taraftan A şirketinin 2,14 milyon TL değerinde İngiliz Sterlini cinsinden finansal yükümlülüğünün bulunduğu ve bunun tamamının kısa vadeli yükümlülüklerden oluştuğu görülmektedir. Buna göre A şirketinin 2017 y1lı dönem sonu itibariyle 13,62 milyon TL değerinde İngiliz Sterlini cinsinden net döviz pozisyonu fazlası olduğu ortaya çıkmıştır. Sonuç olarak A şirketinin 2017 yılı dönem sonu itibariyle tüm döviz varlıkları ve yükümlülükleri birlikte değerlendirildiğinde 564,22 milyon TL değerinde net döviz pozisyonu fazlası olduğu ve bunun 
çok büyük bölümünün $\mathrm{ABD}$ Doları cinsinden finansal varlıklarından oluştuğu ortaya çıkmıştır. Buna göre A şirketinin fonksiyonel para biriminin Avro olduğu göz önünde bulundurulduğunda EUR/USD paritesinden etkilenme düzeyinin yüksek olduğu ve ABD Dolarının Avro karşısında değer kazanması durumunda varlıklarının değer kazanacağ 1 aksi durumda ise varlıklarının değer kaybedeceği söylenebilir. Son olarak A şirketinin döviz kuru riskinden etkilenmeyen türev ürünlerinin bulunduğu ve bunun 61,14 milyon TL'sinin aktif karakterli ABD Doları cinsi türev ürünlerden, 60,96 milyon TL'sinin ise İngiliz Sterlini cinsi türev ürünlerden oluştuğu görülmektedir.

Tablo 3'de B şirketi incelendiğinde B şirketinin yaklaşık 8,1 milyar TL değerinde Avro cinsinden finansal varlığının bulunduğu bunun 7,7 milyar TL'sinin dönen varlıklardan oluştuğu görülmektedir. Diğer taraftan B şirketinin yaklaşık 16,2 milyar TL değerinde Avro cinsinden finansal yükümlülüğünün bulunduğu ve bunun da yaklaşık 13,3 milyar TL'sinin uzun vadeli yükümlülüklerden oluştuğu görülmektedir. Buna göre B şirketinin 2017 yılı dönem sonu itibariyle 8,15 milyar TL değerinde Avro cinsinden net döviz pozisyonu açığı olduğu ortaya çıkmıştır. Yine B şirketinin 1,2 milyar TL değerinde Türk Lirası cinsinden finansal varlığının bulunduğu bunun hemen hemen tamamının dönen varlıklardan oluştuğu görülmektedir. Diğer taraftan B şirketinin yaklaşık 5,2 milyar TL değerinde Türk Lirası cinsinden finansal yükümlülüğünün bulunduğu bunun hemen hemen tamamının kısa vadeli yükümlülüklerden oluştuğu görülmektedir. Buna göre B şirketinin 2017 y1lı dönem sonu itibariyle 3,9 milyar TL değerinde Türk Lirası cinsinden net döviz pozisyonu açığı olduğu ortaya çıkmıştır. B şirketinin Japon Yeni para biriminden varlık ve yükümlülüklerine bakıldığında 50 milyon TL değerinde Japon Yeni cinsinden finansal varlığının bulunduğu bunun tamamının dönen varlıklardan oluştuğu görülmektedir. Diğer taraftan B şirketinin 8,75 milyar TL değerinde Japon Yeni cinsinden finansal yükümlülüğünün bulunduğu ve bunun hemen hemen tamamının uzun vadeli yükümlülüklerden oluştuğu görülmektedir. Buna göre $\mathrm{B}$ şirketinin 2017 yılı dönem sonu itibariyle 8,7 milyar TL değerinde Japon Yeni cinsinden net döviz pozisyonu açığı olduğu ortaya çıkmıştır. Sonuç olarak B şirketinin 2017 yılı dönem sonu itibariyle tüm döviz varlıkları ve yükümlülükleri birlikte değerlendirildiğinde yaklaşık 20,8 milyar TL değerinde net döviz pozisyonu açığı olduğu ve bunun büyük bölümünün Avro ve Japon Yeni cinsinden finansal yükümlülüklerden kaynaklandığ 1 ortaya çıkmıştır. Buna göre $\mathrm{B}$ şirketinin fonksiyonel para biriminin ABD Doları olduğu ve bu şirketin tüm yabancı para birimlerinde net döviz pozisyonu açığının olduğu göz önünde bulundurulduğunda Avro'nun bu para birimleri karşısında değer kaybetmesi durumunda yükümlülüklerinin artacağı aksi durumda ise yükümlülüklerinin azalacağı söylenebilir.

Tablo 3'de A ve B şirketlerinin 2017 y1lına ait yabancı para cinsinden döviz pozisyonları vadelerine göre değerlendirildiğinde A şirketinin ABD Doları cinsinden finansal varlıklarının dönen varlık payının yüksek olduğu ABD Doları cinsinden yükümlülüklerinin ise uzun vadeli yükümlülük payının yüksek olduğu dikkat çekmektedir. Bu durum A şirketinin ABD Doları cinsinden çalışma sermayesinin yüksek düzeyde pozitif olduğu ve bunun uzun vadeli ABD Doları cinsinden finanse edildiği söylenebilir. Buna göre A şirketinin kısa dönemli kur dalgalanmalarından yüksek düzeyde etkilenebileceği olasıdır. Yine Tablo 3'de B şirketinin Avro ve Japon Yeni cinsinden finansal varlıklarının dönen varlık payının yüksek olduğu diğer taraftan Avro ve Japon Yeni cinsinden yükümlülüklerinin ise uzun vadeli yükümlülük payının yüksek olduğu dikkat çekmektedir. Buna göre A şirketine benzer şekilde B şirketinin de yabancı para cinsinden çalışma sermayesinin yüksek düzeyde pozitif olduğu ve kısa dönemli kur dalgalanmalarından yüksek düzeyde etkilenebileceği söylenebilir.

Çalışmanın amacı doğrultusunda tablo 3'de yer alan şirketlerin 2017 yılına ait döviz pozisyonlarından yola çıkılarak çalışmanın yapıldı ğı tarih itibariyle aynı pozisyonda kaldıkları varsayılarak kur riskinden ne kadar etkilenmiş olabilecekleri hesaplanmıştır. Söz konusu hesaplamalar şirketlerin 2017 dönem sonu finansal raporlarını hazırladıkları 31.12.2017 tarihi ile çalışmanın yapıldığı 01.08.2018 tarihi arasındaki Türkiye Cumhuriyet Merkez Bankası (TCMB)'nın yayınladığı alış kurlarının ortalaması alınmak suretiyle gerçekleştirilmiştir. Söz konusu döviz kurları aşağıda verilmiştir.

\section{Aralık 2017:}

$\mathrm{EUR} / \mathrm{USD}=1,1972, \quad \mathrm{EUR} / \mathrm{TL}=4,5155$, $\mathrm{EUR} / \mathrm{GBP}=0,8888, \quad \mathrm{USD} / \mathrm{TL}=3,7719$, $\mathrm{USD} / \mathrm{JPY}=112,590$ 
01.01.2018-01.08.2018 Ortalama:
$\mathrm{EUR} / \mathrm{USD}=1,2047$,
$\mathrm{EUR} / \mathrm{GBP}=0,8825$,
$\mathrm{USD} / \mathrm{JPY}=109,146$

Tablo 4'de Türkiye'deki halka açık havayolu yolcu taşımacıllı̆ 1 şirketlerinin 2017 yılına ait döviz kuru duyarlılık analizi sunulmuştur.

Tablo 4. Türkiye'deki halka açık havayolu yolcu taşımacılığı şirketlerinin döviz kuruna karşı duyarlılıkları

\begin{tabular}{|c|c|c|c|c|}
\hline \multicolumn{2}{|c|}{ Milyon TL } & Net Döviz Po- & \multicolumn{2}{|c|}{ Gerçekleşen Değişim ${ }^{1}$} \\
\hline \multirow{10}{*}{ A Şirketi } & Net ABD Doları (USD) Pozisyonu & 573,38 & \multirow{3}{*}{$\begin{array}{c}\text { USD/EUR } \\
\mathbf{- 0 , 5 6 \%}\end{array}$} & $-3,21$ \\
\hline & USD Riskten Korunan Kısım & 61,14 & & $-0,34$ \\
\hline & USD Net Etki & 634,52 & & $-3,55$ \\
\hline & Net Türk Lirası (TL) Pozisyonu & $-22,77$ & \multirow{3}{*}{$\begin{array}{l}\text { TL/EUR } \\
\mathbf{- 1 1 , 5 0 \%}\end{array}$} & 2,62 \\
\hline & TL Riskten Korunan Kisım & - & & - \\
\hline & TL Net Etki & $-22,77$ & & 2,62 \\
\hline & Net İngiliz Sterlini (GBP) Pozisyonu & 13,62 & \multirow{3}{*}{$\begin{array}{c}\text { GBP/EUR } \\
\mathbf{0 , 7 1 \%}\end{array}$} & 0,10 \\
\hline & GBP Riskten Korunan Kisım & $-60,96$ & & $-0,43$ \\
\hline & GBP Net Etki & $-47,34$ & & $-0,34$ \\
\hline & TOPLAM ETKİ & & & $-1,27$ \\
\hline \multirow{10}{*}{ B Şirketi } & Net Avro Pozisyonu & -8.151 & \multirow{3}{*}{$\begin{array}{c}\text { EUR/USD } \\
\mathbf{0 , 5 6 \%}\end{array}$} & $-45,65$ \\
\hline & Avro Riskten Korunan Kisım & - & & - \\
\hline & Avro Net Etki & -8.151 & & $-45,65$ \\
\hline & Net Türk Lirası (TL) Pozisyonu & -3.937 & \multirow{3}{*}{$\begin{array}{l}\text { TL/USD } \\
\mathbf{- 1 1 , 0 4 \%}\end{array}$} & 434,64 \\
\hline & TL Riskten Korunan Kısım & - & & - \\
\hline & TL Net Etki & -3.937 & & 434,64 \\
\hline & Net Japon Yeni (JPY) Pozisyonu & -8.708 & \multirow{3}{*}{$\begin{array}{c}\text { JPY/USD } \\
\mathbf{3 , 0 6 \%}\end{array}$} & $-266,46$ \\
\hline & JPY Riskten Korunan Kisım & - & & - \\
\hline & JPY Net Etki & -8.708 & & $-266,46$ \\
\hline & TOPLAM ETKI & & & 122,53 \\
\hline
\end{tabular}

1- 01.01.2018-01.08.2018 tarihleri arasında gerçekleşen ortalama döviz kurunun 2017 yılı dönem sonundaki döviz kuruna karşı değişimini ifade eder.

Tablo 4 incelendiğinde A şirketinin ABD Doları cinsinden net döviz pozisyonunun pozitif olduğu dolayısı ile ABD Doları'nın Avro karşısında değer kazanması durumunda şirketin varlıklarının artacağ 1 , aksi durumda da şirketin varlıklarının azalacağı anlaşı1maktadır. ABD Doları'nın Avro karşısındaki durumu analiz edildiğinde 2018 dönem başından bu yana ABD Doları'nın Avro karşısında ortalama \%0,56 düzeyinde değer kaybettiği tespit edilmiştir. Buna göre A şirketinin 2017 yılı dönem sonu bilançosundaki ABD Doları cinsinden net döviz pozisyonu aynı kaldığ 1 varsayıld1ğında, şirketin ABD Doları para biriminden finansal varlıklarının 3,21 milyon TL değer kaybettiği buna ek olarak şirketin ABD Doları cinsinden aktif karakterli türev ürünlerinin de 340 bin TL değer kaybettiği toplamda şirketin ABD Doları cinsinden varlıkları 3,55 milyon TL değerinde azaldığı ortaya çıkmaktadır. A şirketinin TL para biriminden döviz pozisyonu incelendiğinde şirketin TL cinsinden net döviz pozisyonu- nun negatif olduğu görülmektedir. TL'nin Avro karş1sindaki durumu analiz edildiğinde ise TL'nin ortalama $\% 11,50$ düzeyinde değer kaybettiği tespit edilmiştir. Buna göre A şirketinin 2017 yılı dönem sonu bilançosundaki Türk Lirası cinsinden net döviz pozisyonu aynı kaldığı varsayıldığında şirketin TL cinsinden yükümlülüklerinin 2,62 milyon TL değerinde azaldığı ortaya çıkmıştır. Yine A şirketinin İngiliz Sterlini para biriminden döviz pozisyonu incelendiğinde şirketin İngiliz Sterlini cinsinden net döviz pozisyonunun pozitif olduğu görülmektedir. İngiliz Sterlini'nin Avro karş1sindaki durumu analiz edildiğinde ise İngiliz Sterlini'nin ortalama \%0,71 düzeyinde değer kazandığ tespit edilmiştir. Buna göre A şirketinin 2017 y1lı dönem sonu bilançosundaki İngiliz Sterlini cinsinden net döviz pozisyonu aynı kaldığı varsayıldığında şirketin İngiliz Sterlini cinsinden varlıklarının 10 bin TL değerinde arttığı ortaya çıkmıştır. Diğer yandan şirketin İngiliz Sterlini cinsinden pasif karakterli türev ürünleri- 
nin de 43 bin TL değer kaybettiği toplamda şirketin İngiliz Sterlini cinsinden varlıklarının 34 bin TL değerinde azaldığı ortaya çıkmaktadır. Bu bulgular ışığında A şirketinin 2017 y1lı dönem sonu bilançosundaki net döviz pozisyonu aynı kaldığı varsayıldığında şirketin döviz kurlarındaki değişimden etkilenerek varlıklarının 1,27 milyon TL civarında değer kaybettiği ortaya çıkmaktadır. Bu değer kaybının oluşmasında en büyük payın ise ABD Doları'nın Avro karşısında değer kaybetmesi olduğu söylenebilir.

Tablo 4'de B şirketinin Avro cinsinden net döviz pozisyonunun negatif olduğu dolayısı ile Avro'nun ABD Dolar'ı karşısında değer kazanması durumunda şirketin yükümlülüklerinin artacağ 1 , aksi durumda da şirketin yükümlülüklerinin azalacağı bilinmektedir. Avro'nun ABD Doları karşısındaki durumu analiz edildiğinde 2018 dönem başından bu yana Avronun ortalama \%0,56 düzeyinde değer kazandığ 1 tespit edilmiştir. Buna göre A şirketinin 2017 yılı dönem sonu bilançosundaki Avro cinsinden net döviz pozisyonu aynı kaldığ 1 varsayıldığında şirketin Avro cinsinden yükümlülüklerinin 45,65 milyon TL değerinde arttığ1 ortaya çıkmıştır. B şirketinin TL para biriminden döviz pozisyonu incelendiğinde şirketin TL cinsinden net döviz pozisyonunun negatif olduğu görülmektedir. TL'nin ABD Doları karşısındaki durumu analiz edildiğinde ise TL'nin ortalama \%11,04 düzeyinde değer kaybettiği tespit edilmiştir. Buna göre $\mathrm{B}$ şirketinin 2017 y1lı dönem sonu bilançosundaki Türk Lirası cinsinden net döviz pozisyonu aynı kaldığ 1 varsayıld1ğında şirketin TL cinsinden yükümlülüklerinin 434,64 milyon TL değerinde azaldığı ortaya çıkmıştır. Yine B şirketinin Japon Yeni para biriminden döviz pozisyonu incelendiğinde şirketin JPY cinsinden net döviz pozisyonunun negatif olduğu görülmektedir. Japon Yeni'nin ABD Doları karşısındaki durumu analiz edildiğinde ise Japon Yeni'nin ortalama \%3,06 düzeyinde değer kazandığı tespit edilmiştir. Buna göre A şirketinin 2017 yılı dönem sonu bilançosundaki Japon Yeni cinsinden net döviz pozisyonu aynı kaldığ 1 varsayıldığında şirketin JPY cinsinden yükümlülüklerinin 266,46 milyon TL değerinde arttığı ortaya çıkmıştır. B şirketinin 2017 y1lı dönem sonu finansal raporu incelendiğinde bu şirketin herhangi bir döviz kuruna yönelik türev araç kullanmadığı ortaya çıkmıştır. Bu bulgular 1şı̆̆ında B şirketinin 2017 yılı dönem sonu bilançosundaki net döviz pozisyonu aynı kaldığı varsayıldı- ğında şirketin döviz kurlarındaki değişimden etkilenerek varlıklarının 122,53 milyon TL civarında değer kazandığı ortaya çıkmaktadır. Bu artışın oluşmasında en büyük payın ise TL cinsinden döviz pozisyonunun negatif oluşu ve TL'nin ABD Doları karşısında ciddi oranda değer kaybetmesi olduğu söylenebilir.

\section{Sonuç}

$\mathrm{Bu}$ çalışmanın temel amacı, payları Borsa İstanbul'da işlem gören havayolu yolcu taşımacıllğı şirketlerinin faaliyet raporlarını inceleyerek döviz kuru risklerini ve buna yönelik hangi önlemlerin alındığını değerlendirmektir. $\mathrm{Bu}$ doğrultuda Türkiye'deki halka açık havayolu şirketlerinin 2017 yılına ait finansal raporları incelenmiştir. Çalışmada şirketlerin bulguları yorumlanırken herhangi bir spekülasyona yol açmamak adına şirketler "A" ve "B" olarak kodlanmıştır.

Çalışmada A ve B şirketlerinin 2017 dönem sonu finansal raporları incelendiğinde A şirketinin faaliyetlerini yürütmede baz aldığ 1 fonksiyonel para biriminin Avro olduğu, B şirketinin ise ABD Doları olduğu tespit edilmiştir. Bu bağlamda söz konusu şirketlerin yabancı para biriminden finansal varlık ve yükümlülükleri incelendiğinde A şirketinin ağırlıklı olarak ABD Doları cinsinden finansal varlık ve yükümlügünün bulunduğu, B şirketinin ise ağırlıklı olarak Avro ve Japon Yeni para birimlerinden finansal varlık ve yükümlüğünün bulunduğu ortaya çıkmıştır. Ayrıca şirketlerin kur riskinden korunmak amaciyla türev ürün kullanıp kullanmadıkları incelendiğinde A şirketinin aktif karakterli ABD Doları cinsinden ve pasif karakterli İngiliz Sterlini cinsinden türev araçlara sahip olduğu, B şirketinin ise yabanc1 para cinsinden herhangi bir türev ürüne sahip olmadığı ortaya çıkmıştır. Çalışmanın temel amacı doğrultusunda şirketlerin döviz pozisyonları incelendiğinde $\mathrm{A}$ şirketinin ağırlıklı olarak ABD Doları para biriminden net döviz varlık pozisyonunun bulunduğu, B şirketinin ise ağırlıklı olarak Avro ve Japon Yeni para birimlerinden net döviz yükümlülük pozisyonuna sahip olduğu görülmüştür. Ayrıca B şirketinin Türk Lirası para biriminden net döviz yükümlülügünün de dikkate değer bir oranda olduğu dikkat çekmiştir. Bu bağlamda A ve B şirketlerinin kur riskine ne oranda maruz kaldıkları tespit edilmek istenmiş ve buna yönelik çalışmanın yapıldığı 01.08.2018 tarihi ile 2017 yılı dönem sonu tarihi arasındaki döviz kurlarının ortalaması alınmış ve çıkan sonuçların 2017 dönem sonundaki döviz kurlarına göre değişimi elde edilmiştir. 
Elde edilen kur değişimleri şirketlerin net döviz pozisyonlarına ne derece etki ettiği analiz edilmiştir. Buna göre ABD Doları'nın Avro karşısında \%0,56 değer kaybettiği ve A şirketinin ABD Doları cinsinden net döviz fazlası olduğundan dolayı bu değişimden negatif yönde etkilendiği ortaya çıkmıştır. B şirketinin ise Avro cinsinden net döviz açığı olduğundan dolayı bu değişimden yine negatif yönde etkilendiği görülmüştür. Diğer döviz kurlarına bakıldığında Türk Lirası'nın Avro karşısında \%11,50 değer kaybettiği ve A şirketinin Türk Lirası cinsinden net döviz açığı olduğundan dolayı bu değişimden pozitif yönde etkilendiği ortaya çıkmıştır. Türk Lirası'nın ABD Doları karşısında da $\% 11,04$ değer kaybettiği dikkate alındığında B şirketinin Türk Lirası cinsinden net döviz açığı olması sebebiyle yine bu değişimden pozitif yönde etkilendiği saptanmıştır. İngiliz Sterlinindeki değişim incelendiğinde ise bu döviz cinsinin Avro karşısında \%0,71 değer kazandığı ancak A şirketinin İngiliz Sterlini cinsinden net döviz açığının çok yüksek tutarda olmaması nedeni ile bu değişimden çok fazla etkilenmediği ortaya çıkmıştır. Diğer taraftan B şirketinin Japon Yeni cinsinden net döviz açığııın yüksek tutarda olması ve Japon Yeni’nin ABD Doları karşısında \%3,06 değer kaybetmesinden dolayı B şirketinin bu değişimden negatif yönde etkilendiği görülmektedir. Tüm bulgular birlikte değerlendirildiğinde A şirketinin döviz kurundaki değişimler neticesinde 1,27 milyon TL değerinde değer kaybına uğradığı ve bu kaybın daha çok ABD Doları'nın Avro karşısındaki değer kaybından kaynaklandığı, B şirketinin ise 122,53 milyon TL değerinde değer kazandığ 1 ve bu artışın daha çok Türk Lirası cinsinden finansal yükümlülügün ve Türk Lirası'nın ABD Doları karşısındaki değer kaybının yüksek oluşundan kaynaklandığı ortaya çıkmıştır.

Sonuç olarak Türkiye'deki halka açık havayolu yolcu taşımacıllğ 1 şirketlerinin döviz kurundaki dalgalanmalardan etkilenmeye açık oldukları ve kur riskine maruz kaldıkları ortaya çıkmıștır. Bu șirketlerden A şirketinin kur riskinden korunmak amaciyla türev ürünler kullandığı ancak yeterli düzeyde bir korunmanın sağlanamadığı, B şirketinin döviz kuru riskine yönelik herhangi bir türev ürününün bulunmadığı görülmektedir. Bu bağlamda Türkiye'deki halka açık havayolu yolcu taşımacıllı̆̆ şirketlerinin döviz kuru riski politikalarını gözden geçirmeleri ve kur dalgalanmalarına karşı tedbir almaları önerilmektedir. Böylece dö- viz pozisyonlarının kur dalgalanmalarından etkilenmesi ile ortaya çıkan değer artışı veya azalışlarının önüne geçebileceklerdir. Havayolu yolcu taşımacıllı̆ 1 şirketlerinin döviz kurundan dolaylı olarak etkilendiği bir diğer husus da kullanılan yakıtların maliyetidir. Bilindiği üzere yakıt maliyetleri ABD Doları'na endeksli olduğundan Dolar'daki dalgalanmalar yakıt maliyetlerini de önemli ölçüde etkilemektedir. Buna yönelik olarak şirketlerin yakıt alımıyla ilgili türev ürünleri kullanmaları kaçınılmaz olmaktadır. Çalışmada incelenen şirketlerin finansal raporlarında yakıt alımları ile ilgili türev ürünlerin bulunduğu ve bunların finansal risk kapsamında değerlendirildiği görülmüştür. Bu çalışmada Türkiye'deki halka açık havayolu taşımacılığı şirketlerinin 2017 y1lına ait kur riskine ilişkin analizler sadece şirketlerin yabancı para cinsinden finansal varlıkları ve yükümlülükleri üzerinden gerçekleştirilmiştir. Dolayısı ile çalışma sınırlı bir süreyi ve sınırlı sayıdaki havayolu yolcu taşımacılığı şirketini kapsamaktadır. İleride yapılacak çalışmalarda yakıt maliyetleri de dikkate alınarak daha çok şirket ile daha uzun süreli analizler gerçekleştirilebilir.

\section{Kaynakça}

Akkaş, M.E. (2015). Finansal Olmayan Şirketlerde Döviz Kuru Riski Yönetimi: Borsa İstanbul Şirketleri Üzerine Ampirik Bir Çalışma (Doktora Tezi), Ankara Üniversitesi.

Altay, E. (2014), Bankacllikta risk, İstanbul: Derin Yayınlar1.

Businessht (2018). https://www.businessht.com.tr/piyasalar/haber/2062204-reel-sektorun-kisa-vadeli-dis-borcstoku-tarihi-zirvede adresinden 17.07.2018 tarihinde erişildi.

Büberkökü, Ö. (2014). Kur riski duyarlılığı, kur riski ölçümü ve türev ürün-kur riski ilişkisi: Türk mevduat bankaları üzerine bir uygulama (Doktora Tezi), Çukurova Üniversitesi.

Doğanay, M. (2016). Döviz kuru riski yönetimine sektörel bir yaklaşım. Uluslararası Kültürel ve Sosyal Araştırmalar Dergisi (UKSAD), 2(Special Issue 1), 149-164.

Doğukanl, H., Özmen, M. ve Yücel, E. (2010). İMKB'de sektörel açıdan döviz kuru duyarlılığının incelenmesi. Çukurova Üniversitesi Sosyal Bilimler Enstitüsü Dergisi, 19(3), 63-86. 
Gökçe, A. ve Sarıtaş, H. (2017). Döviz kurlarındaki değişmelerin Türkiye'deki özel sermayeli bankaların bilançoları üzerine etkileri. Pamukkale Üniversitesi Sosyal Bilimler Enstitüsü Dergisi, (28), 1-18.

Helleiner, E. (1996), States and the reemergence of global finance: From Bretton Woods to the 1990s. London: Cornell University Press.

Kamuyu Aydınlatma Platformu
https://www.kap.org.tr/tr/Sektorler/
15.07.2018 tarihinde erişildi.
adresinden

Kiliç, C. ve Bayar, Y. (2014). Effects of real exchange rate volatility on tourism receipts and expenditures in Turkey. Advances in Management and Applied Economics, 4(1), 89-101.

Kutukız, D. (2005). Turizm sektöründe döviz riski ve korunma yöntemleri. Muhasebe ve Finansman Dergisi, (28), 198-207.

Mutluay, A. H. ve Turaboğlu, T.T. (2013). Döviz kuru değişimlerinin firma performansına etkileri: Türkiye örneği. BDDK Bankacılık ve Finansal Piyasalar, 7(1), 59-78.

Shapiro, A. C. 2013. Multinational financial management, 10th Edition, New Jersey: John Wiles and Sons Inc.

Türkiye Cumhuriyet Merkez Bankası (2018), http://www.tcmb.gov.tr/ 02.08.2018 adresinden tarihinde erişildi.

Ünal, O. ve Altın, H. (2010). Döviz kur riski ile şirket değeri arasındaki ilişkinin İMKB otomotiv sektöründe analizi. Dumlupınar Üniversitesi Sosyal Bilimler Dergisi, (26), 1-11.

\section{Extended abstract in English}

It has been observed recently that the high fluctuation in exchange rates has caused losses in companies that had currency deficits. Especially the price changes between $2 \%$ and $5 \%$ a day in Dollar may cause losses in the real sector, which buys raw materials with Dollars, and which sells them in TL to the domestic market. One of the sectors that was affected by the exchange rates at the highest level is the tourism sector in Turkey. Due to the fact that nearly all of the business revenues are carried out with foreign currencies, the changes in the exchange rates are reflected in the tourism businesses. The fact that the fuel costs of the airline companies are based on foreign currency might cause that they suffer more losses because of the fluctuations in exchange rates. In this respect, the purpose of the present study is to evaluate the exchange rate risks of airline passenger transportation companies whose shares are traded in Borsa Istanbul by examining the activity reports of these companies and to determine the measures taken for this condition. For this purpose, the 2017 financial reports of 2 companies, which act in the field of airline passenger transportation, and whose shares are traded in Borsa Istanbul, were examined.

Proportional analyzes were carried out by using secondary data. In line with the purpose of the study, the financial reports of the airline passenger transportation companies, whose shares are traded in Borsa Istanbul (BIST), were analyzed. The data of the public passenger transport and airline companies in Turkey were obtained from the Public Disclosure Platform (2018), from the activity reports they released in their websites, and from the Thomson \& Reuters EIKON database. There are 2 airway passenger transportation companies that are publicly traded in Turkey. These companies are the Turkish Airlines Inc. and Pegasus Air Transportation Inc. The companies were encoded as $\mathrm{A}$ and $\mathrm{B}$ when the findings were interpreted in the present study to avoid any speculations.

In the present study, when the financial reports of the end of the year 2017 belonging to the A and B Companies were examined, it was determined that the functional currency, which A Company based its activities on Euro; and the currency of the B Company was US Dollars. In this respect, when the foreign currency unit of these companies and their financial assets and liabilities were examined, it was determined that $\mathrm{A}$ Company mostly had financial assets and liabilities in US Dollars, and the B Company had them is Euros and JPY. In addition, when the derivative products usage status of the companies for the purpose of ensuring protection from currency risk was examined, it was determined that the A Company had derivative financial instruments in US Dollars with an active character, and in Pound with passive character, and the B Company had no derivative financial instruments in any foreign currency. In line with the basic purpose of the study, when the currency positions of the companies were examined, it was determined that the A Company had mostly net currency asset position in US Dollars, and the B Company had mostly net currency liability position in Euros and JPY. In addition, it was also observed that the B Company had net currency liabilities in Turkish Liras at a considerable amount. In this context, the extent of the exposure of the companies to currency risk was determined, and the average of the currency 
rates in 01.08 .2018 and the end of the year 2017, which is the period covered by the present study, and the change according to the currency rates were obtained. The effect of the currency changes on the net currency positions of the companies was also analyzed. In this respect, since the US Dollar lost value compared to Euro at a rate of $0.56 \%$, and since the A Company had excessive amounts of US Dollars, it was determined that this company was affected negatively by this change. Since the B Company, on the other hand, had currency deficit in Euros, it was also affected negatively by this change. When other currencies were considered, it was determined that Turkish Lira lost value compared to Euro at a rate of $11.50 \%$, and since the A Company had a net currency deficit in Turkish Liras, it was determined that this company was affected positively by this change. When the fact that Turkish Lira lost value at a rate of $11.04 \%$ compared to the US Dollar, since the B Company had net currency deficit in Turkish Liras, again, it was determined that this company was affected positively by this change. On the other hand, when the change in the Pound was examined it was determined that it increased at a rate of $0.71 \%$ compared to Euro; however, the A Company was not affected much by this change because its net currency deficit in Pound was not high. It was also determined that the B Company was affected negatively by this change because it had high net currency deficit in JPY, and the JPY lost value at a rate of $3.06 \%$ when compared to the US Dollar. When all these findings were evaluated together, it was determined that the A Company had a loss at a rate of 1.27 million TL as a result of the changes in the currency rates, and this loss stemmed mostly from the value loss of the US Dollar when compared to Euro; and the Company, on the other hand, earned 122.53 million TL. This increase stemmed mostly from the high financial liability in Turkish Lira and high value loss of Turkish Lira when compared to the US Dollar.

As a result, it was determined that the public airway passenger transportation companies in Turkey are open to the influences of the fluctuations in foreign currency, and are exposed to currency risk. It was observed that the A Company used derivative financial products for the purpose of protecting itself from currency risk; however, this protection was not at an adequate level; and the B Company did not use any derivative financial instruments for the protection against currency risk. In this respect, it is recommended that the public airway passenger transportation companies in Turkey should revise their currency risk policies, and take precautions for currency fluctuations. In this way, they may avoid the increases and decreases observed due to the fluctuations in currency positions. 